\title{
SALUD MENTAL EN COLOMBIA: ATENCIÓN BIOMÉDICA DE LOS TRASTORNOS MENTALES, NO EL CUIDADO DE LAS PERSONAS Y COMUNIDADES
}

\section{Edwin Herazo Acevedo ${ }^{1}$}

\section{Resumen:}

Pensar la salud mental en Colombia se ha convertido en todo un desafío, especialmente en las condiciones y contextos que nos plantea las realidades de nuestro país. Históricamente se han trasgredido los límites del respeto y de la dignidad y con el argumento por la protección, se han vulnerado derechos fundamentales de los pacientes. Atender el trastorno mental, desde una perspectiva integral es el desafío disciplinar vigente que nos debe ocupar y llamar a la reflexión.

Palabras clave: trastornos mentales, salud mental, atención a la salud mental

\section{MENTAL HEALTH IN COLOMBIA: BIOMEDICAL CARE OF MENTAL DISORDERS, NOT CARE OF INDIVIDUALS AND COMMUNITIES}

\begin{abstract}
:
thinking about mental health in Colombia has become a challenge, especially in the conditions and contexts posed by the realities of our country. Historically, the limits of respect and dignity have been transgressed and, under the argument of protection, patients' fundamental rights have been violated. Attending to mental disorders from an integral perspective is the current disciplinary challenge that should occupy us and call for reflection.
\end{abstract}

Keywords: mental disorders, mental health, mental health assistance

(C) 2021 Fundación Universitaria Juan N. Corpas (FUJNC).

Artículo Open Access bajo la Licencia Creative Commons

Atribución-NoComercial-Compartirlgual 4.0 Internacional.

DOI: https://doi.org/10.26752/revistaparadigmassh.v3iSupl.1.610

\footnotetext{
${ }^{1}$ Médico psiquiatra, docente e investigador. Grupo de Investigación del Comportamiento Humano. Bogotá, D.C.,
}

Colombia. ORCID 0000-0002-9461-7997.Autor de correspondencia: eh@comportamientohumano.org 
El campo de la salud mental representa un desafío para las sociedades alrededor del mundo. Esta afirmación no hace referencia solo al hecho de que, de acuerdo con las cifras de los estudios de carga de enfermedad, las causas relacionadas con salud mental año tras año suben escalones en la lista de enfermedades con mayor impacto en la población a nivel mundial, si no a aquellas condiciones y situaciones que raras veces se hacen visibles por parte de los gobiernos: insatisfacción laboral, frustraciones derivadas de no poder realizar su proyecto de vida o alcanzar las metas impuestas por el contexto social y cultural o, incluso, autoimpuestas, redes de apoyo ineficientes o en ocasiones inexistentes, entornos generadores y favorecedores de discapacidad psicosocial, violencia de género, abuso infantil, violencia sexual, escolar y laboral (Instituto Nacional de Salud, 2017).

El reto de conservar, promover y recuperar la salud mental de las personas y comunidades debe sortearse en medio de condiciones sociales, económicas, políticas y ambientales adversas. Adicionalmente, los distintos sectores que se intersectan en el campo de la salud mental, lejos de integrarse y afrontar este desafío de una manera más coherente y consistente, terminan por potenciar la fragmentación múltiple que ha acompañado a la salud mental desde los inicios de su configuración como campo a mediados del siglo XX.

En medio de la fragmentación del campo de la salud mental, el sector salud ha sido tradicionalmente el titular de su gestión, exponiendo una enorme dificultad: se ha responsabilizado por la atención de los trastornos mentales, pero no del cuidado de las personas a quienes se les han diagnosticado estos trastornos. Se han dejado de lado las personas, en sí mismas, para centrarse en la presencia de los trastornos mentales de las personas. Esto es consecuencia del predominio de una perspectiva biomédica excluyente de los demás factores que rodean el sufrimiento y el malestar psíquico de las personas, especialmente en un país donde la violencia producto del prolongado conflicto sociopolítico tiene a su haber desplazamientos forzados, homicidios, secuestros, violencia sexual y de género y suicidios. En ese contexto de irrespeto a la diversidad ideoló- gica, política, cultural, sexual y comportamental el poder hegemónico de la perspectiva biomédica, anclada en un sistema de salud que la favorece, potencia y de la cual se lucran sus actores, lo biomédico termina por encubrir lo psicosocial (Herazo, 2014).

Lo anterior se plasma en la cotidianidad del sistema de salud, cuando, a pesar de la promulgación de la Ley Estatutaria de la Salud (Ley 1751 de 2015), en la práctica la autoridad sanitaria nacional asume que todo aquello que no hace parte de las intervenciones en salud, en sentido estricto, es decir, aquello que desborda los límites de lo biomédico, pasa a hacer parte de algo que denominaron "socio-sanitario". Es en esa categoría a la que asignan las acciones de cuidado de las personas con diagnósticos de trastornos mentales.

El trato marginal que se le ha prodigado al cuidado impone una sobrecarga física, emocional y económica a las personas, familias y comunidades, que no cuentan con las condiciones para brindar un cuidado dirigido a evitar la exclusión de las personas con diagnósticos de trastornos mentales y favorecer su recuperación e integración real y completa a las comunidades de las que hacen parte.

El cuidado de las personas con diagnósticos de trastornos mentales no debe asumirse como una prolongación de la vigilancia y control propios de los antiguos manicomios pero que están muy incorporados a la prestación tradicional de los servicios de salud mental, en los que no siempre se reconoce la autonomía, el libre desarrollo de la personalidad, la capacidad para tomar decisiones en torno a sus vidas e incluso a estas personas se les llegó a negar su capacidad jurídica por el solo hecho de reunir los criterios establecidos para diagnosticar un trastorno mental. Es como si el tiempo hubiera quedado congelado desde aquel Código Civil Colombiano de 1887. En este aspecto, la Ley 1996 de 2019 ("Por medio de la cual se establece el régimen para el ejercicio de la capacidad legal de las personas con discapacidad mayores de edad"), está Ilamada a ser una herramienta que permita reparar el daño y la vulneración continua a los derechos de las personas con trastornos mentales. 
El cuidado a las personas con trastornos mentales deberá ser emancipador y respetuoso de los derechos, o será nuevamente un instrumento de sometimiento, violencia y de vulneración sistemática de los derechos humanos de quienes han recibido un diagnóstico de trastorno mental.

\section{Referencias Bibliográficas}

1. Instituto Nacional de Salud (2017). Guía metodológica para el observatorio nacional de salud mental. [Fecha de Consulta 5 de Octubre de 2021]. Disponible en: https://www.minsalud.gov.co/sites/ rid/Lists/BibliotecaDigital/RIDE/NS/ED/GCFI/guia-ross-salud-mental.pdf

2. Herazo, Edwin (2014). La salud mental ante la fragmentación de la salud en Colombia: entre el posicionamiento en la agenda pública y la recomposición del concepto de salud. Revista Facultad Nacional de Salud Pública, 32(1),S21-S27. [fecha de Consulta 5 de Octubre de 2021]. ISSN: 0120-386X. Disponible en: https://www.redalyc.org/articulo.oa?id=12058124003.

3. Ley Estatutaria $1751 / 15$ de 16 de Febrero por medio de la cual se regula el derecho fundamental a la salud y se dictan otras disposiciones. Diario Oficial No. 49.427 de 16 de febrero de 2015. Recuperado de: http://www.secretariasenado.gov.co/senado/basedoc/ley_1751_2015.html

4. Ley 1996/19 de 26 de agosto por medio de la cual se establece el régimen para el ejercicio de la capacidad legal de las personas con discapacidad, mayores de edad. Diario Oficial No. 51.057 de 26 de agosto 2019. Recuperado de http://www.secretariasenado.gov.co/senado/basedoc/ ley_1996_2019.html 